\title{
Effectiveness of cigarette warning labels in informing smokers about the risks of smoking: findings from the International Tobacco Control (ITC) Four Country Survey
}

\author{
D Hammond, G T Fong, A McNeill, R Borland, K M Cummings
}

Tobacco Control 2006;15(Suppl III):iii19-iii25. doi: 10.1136/tc.2005.012294

Background: Health warnings on cigarette packages are among the most common means of communicating the health risks of smoking. However, few studies have evaluated the impact of package warnings on consumer knowledge about tobacco risks.

Objective: The aim of the current study was to use nationally representative samples of adult smokers from the United States (USA), the United Kingdom (UK), Canada (CAN), and Australia (AUS) from the International Tobacco Control Four Country Survey (ITC-4) to examine variations in smokers' knowledge about tobacco risks and the impact of package warnings.

See end of article for authors' affiliations

Correspondence to: Dr David Hammond Department of Health Studies and Gerontology, University of Waterloo, 200 University Avenue West, Waterloo, Ontario, N2L 3G1, Canada; dhammond@uwaterloo.ca

Received 19 April 2005 Accepted 19 October 2005
Methods: A telephone survey was conducted with 9058 adult smokers from the following countries: USA ( $n=2138)$, UK $(n=2401)$, CAN $(n=2214)$ and AUS $(n=2305)$. Respondents were asked to state whether they believed smoking caused heart disease, stroke, impotence, lung cancer in smokers, and lung cancer in non-smokers. Respondents were also asked whether the following chemicals are found in cigarette smoke: cyanide, arsenic and carbon monoxide.

Findings: Smokers in the four countries exhibited significant gaps in their knowledge of the risks of smoking. Smokers who noticed the warnings were significantly more likely to endorse health risks, including lung cancer and heart disease. In each instance where labelling policies differed between countries, smokers living in countries with government mandated warnings reported greater health knowledge. For example, in Canada, where package warnings include information about the risks of impotence, smokers were 2.68 (2.41-2.97) times more likely to agree that smoking causes impotence compared to smokers from the other three countries.

Conclusion: Smokers are not fully informed about the risks of smoking. Warnings that are graphic, larger, and more comprehensive in content are more effective in communicating the health risks of smoking.
T obacco use has been identified by the World Health Organization as the leading cause of death and disability in the world. ${ }^{1}$ To date, more than 24 different smokingrelated diseases have been identified, including cardiovascular disease, respiratory disease, and 10 different forms of cancer. $^{2}$

The extent to which smokers understand the magnitude of these health risks has a strong influence on their smoking behaviour. ${ }^{3-5}$ Smokers who perceive greater health risk from smoking are more likely to intend to quit and to quit smoking successfully. ${ }^{67}$ The health risks of smoking are also the most common motivation to quit cited by current and former smokers, as well as the best predictor of long-term abstinence among reasons for quitting. ${ }^{8-10}$

At present, most smokers concede that tobacco use is a health risk; however, important gaps remain in their understanding of these risks. ${ }^{11-14}$ Many smokers are unable to recall specific health effects and most tend to underestimate the scope of these effects. ${ }^{11}{ }^{15-19}$ Even in countries such as Canada, with among the most progressive tobacco control policies in the world, a significant proportion of smokers continue to underestimate the most serious risks of smoking, including heart disease, stroke, and respiratory disease, as well as the risks of environmental tobacco smoke. ${ }^{11} 20$

In addition to the fact that smokers are not fully informed, there are biases in how smokers perceive these risks. In a review of the research literature, Weinstein ${ }^{21}$ found that, although most smokers acknowledge the risk of smoking, they tend to "minimize that risk and show a clear tendency to believe that the risk applies more to other smokers than to themselves" (page 139). Considerably less is known about smokers' knowledge of the constituents of tobacco smoke, including well-known toxicants such as carbon monoxide and cyanide. What little evidence exists suggests a very low level of awareness, ${ }^{22}{ }^{23}$ although the impact of this knowledge remains largely unexplored.

Communicating the health effects of smoking remains a primary goal of tobacco control policy. ${ }^{24}$ Indeed, the World Health Organization's Framework Convention on Tobacco Control (FCTC) states as its first guiding principle that: "Every person should be informed of the health consequences, addictive nature and mortal threat posed by tobacco consumption and exposure to tobacco smoke" (Article 4.1). Cigarette warning labels are among the most widespread policy initiatives implemented to educate smokers. Recent research indicates that graphic warning labels on cigarette packages can increase cessation behaviour among smokers ${ }^{25-27}$; however, despite their prominence among tobacco control policies, only a handful of studies have evaluated the impact of different product warning policies on consumer knowledge about tobacco risks.

A study commissioned by Imperial Tobacco reported an increase in the proportion of smokers who agreed that smoking is dangerous following the introduction of Canada's

Abbreviations: CATI, computer assisted telephone interviewing; FCTC, Framework Convention on Tobacco Control; ITC-4, International Tobacco Control Four Country Survey 


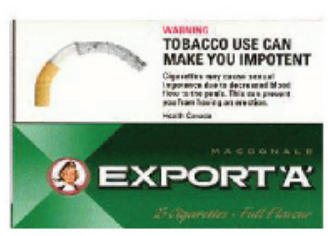

Canada (2001)

-16 rotating warnings

$-50 \%$ of pack face

-colour pictures
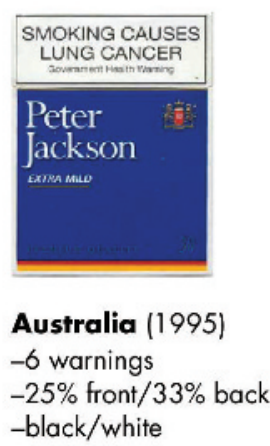

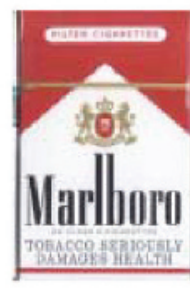

UK (1992)

-6 warnings

$-6 \%$ of face

-black/white
Figure 1 Cigarette package warning labels of the four countries (Canada, Australia, United Kingdom, United States) participating in the International Tobacco Four Country Survey (as of 2002). first warning labels in $1972 .{ }^{28}$ Cross-sectional surveys conducted in Canada during the 1990s found that the majority of smokers reported that package warning labels are an important source of health information and have increased their awareness of the risks of smoking. ${ }^{11}{ }^{29}$ In Australia, Borland ${ }^{30}$ found that, relative to non-smokers, smokers demonstrated an increase in their knowledge of the main constituents of tobacco smoke and identified significantly more disease groups following the introduction of new Australian warning labels in 1995. However, considering the importance of health warnings among tobacco control policies, there is a need for additional research. In particular, there is a need for research that can help policymakers to choose the size and general strength of health warnings from within the general recommendations outlined in the FCTC.

At present, cigarette packages in virtually every country carry warning labels, ${ }^{31}$ yet the size, number, and the way the health information is presented differs notably between countries. Labelling policies range from vague statements of risk (for example, "Smoking can be harmful to your health"), to graphic pictorial depictions of disease. Because of the variation between countries in package warning labels, an opportunity now exists to explore the impact of different warning policies on consumer knowledge. The International Tobacco Control Four Country Survey (ITC-4) is a cohort survey of adult smokers conducted in four countries- the United States (USA), the United Kingdom (UK), Canada (CAN), and Australia (AUS) - that was designed to examine the impact of national-level tobacco control policies, including warning labels. Figure 1 depicts health warnings in the four countries participating in the ITC-4 Survey as of Wave 1 of the survey, conducted in 2002.*

The aim of the current study was to use nationally representative samples of adult smokers from the USA, UK, CAN, and AUS to: (1) examine smokers' knowledge that smoking causes heart disease, stroke, impotence, and lung cancer; (2) to assess smokers' knowledge of the constituents of tobacco smoke, including carbon monoxide, cyanide, and arsenic; and (3) to examine the relationship between health knowledge in each country and that country's tobacco labelling policy.

\section{METHODS}

\section{Sample}

Participants in the ITC-4 Survey were 9058 adult smokers (18 years or older, smoked more than 100 cigarettes in their life, and smoked at least once in the past 30 days) in four countries: CAN $(\mathrm{n}=2114)$, USA $(\mathrm{n}=2138)$, UK

*Note that new UK package warnings (one of 16 text warnings covering $30 \%$ of the package) were implemented in January 2003, following Wave 1 of the ITC-4 survey. $(\mathrm{n}=2401)$, and AUS $(\mathrm{n}=2305)$. Table 1 provides the sample characteristics for each country.

\section{Procedure}

The ITC-4 cohort was constructed from probability sampling methods with telephone numbers selected at random from the population of each country, within strata defined by geographic region and community size. Eligible households were identified by asking a household informant the number of adult smokers. The Next Birthday Method ${ }^{32}$ was used to select the respondent in households with more than one eligible adult smoker.

The survey was conducted using computer assisted telephone interviewing (CATI) software and was completed in two calls: a 10-minute recruitment call was followed one week later by a 40-minute main survey. In order to increase recruitment rates, ${ }^{33}$ participants were mailed compensation equivalent to US\$10 before completing the main survey. Interviews were conducted by two survey firms: Roy Morgan Research (Melbourne, Australia) surveyed Australian and UK respondents, and Environics Research Group (Toronto, Canada) surveyed Canadian and US respondents. All aspects of the interviewer training and calling protocol were standardised across the two survey firms and closely supervised by the ITC-4 team. The present analysis is limited to respondents from Wave 1, conducted between October and December 2002. A full description of the ITC-4 methodology, sample profile, and survey rates, including comparisons with national benchmarks, is available at http://www.itcproject. org.

\section{Measures}

The ITC-4 Survey was standardised across the four countries: respondents in each country were asked the same questions, with only minor variations for colloquial speech.

\section{Demographics and smoking behaviour}

The survey included validated measures of smoking behaviour and quit history. Intention to quit was assessed by asking: "Are you planning to quit in the next month, 6 months, beyond 6 months, or not at all?" Level of education consisted of three categories: high school diploma or lower; technical, trade school, community college, or some university; and university degree. Annual income was categorised into "under \$30 000", "\$30 000-\$59 999", and "\$60 000 and over" for the US, Canadian, and Australian samples. For the UK sample, we used the following categories: "£15 000 or under", "£15 001-£30 000," and "£30 001 and over". Ethnicity was measured using the relevant census question for each country and then analysed as a dichotomous variable to allow for comparisons across countries ("white" $v$ "non-white and mixed race"), except 
Table 1 Characteristics of International Tobacco Four Country Survey (ITC-4) sample by country ( $n=9058$ )

\begin{tabular}{|c|c|c|c|c|c|c|c|c|}
\hline & \multicolumn{4}{|c|}{ Unweighted } & \multicolumn{4}{|l|}{ Weighted } \\
\hline & CAN & AUS & USA & UK & CAN & AUS & USA & UK \\
\hline \multicolumn{9}{|l|}{ Sex } \\
\hline Female & $54.3 \%$ & $52.7 \%$ & $55.2 \%$ & $56.6 \%$ & $45.8 \%$ & $44.5 \%$ & $46.4 \%$ & $49.8 \%$ \\
\hline Male & $45.7 \%$ & $47.3 \%$ & $44.8 \%$ & $43.4 \%$ & $54.2 \%$ & $55.5 \%$ & $53.6 \%$ & $50.2 \%$ \\
\hline \multicolumn{9}{|l|}{ Age } \\
\hline $18-24$ & $15.6 \%$ & $16.8 \%$ & $15.7 \%$ & $8.5 \%$ & $14.3 \%$ & $17.2 \%$ & $15.3 \%$ & $14.2 \%$ \\
\hline $25-39$ & $31.8 \%$ & $36.8 \%$ & $30.9 \%$ & $32.4 \%$ & $33.7 \%$ & $35.5 \%$ & $31.3 \%$ & $33.2 \%$ \\
\hline $40-54$ & $34.5 \%$ & $32.8 \%$ & $33.9 \%$ & $33.9 \%$ & $34.7 \%$ & $32.2 \%$ & $35.8 \%$ & $28.7 \%$ \\
\hline $55+$ & $18.1 \%$ & $13.5 \%$ & $19.6 \%$ & $25.2 \%$ & $17.3 \%$ & $15.1 \%$ & $17.6 \%$ & $24.0 \%$ \\
\hline \multicolumn{9}{|l|}{ Education } \\
\hline 12 years or less & $46.9 \%$ & $66.8 \%$ & $44.1 \%$ & $64.5 \%$ & $47.7 \%$ & $67.8 \%$ & $45.2 \%$ & $63.4 \%$ \\
\hline More than 12 years & $53.1 \%$ & $33.2 \%$ & $55.9 \%$ & $35.5 \%$ & $52.3 \%$ & $32.2 \%$ & $54.8 \%$ & $36.6 \%$ \\
\hline \multicolumn{9}{|l|}{ Ethnicity/language } \\
\hline White/English only & $87.5 \%$ & $86.2 \%$ & $76.4 \%$ & $94.7 \%$ & $88.1 \%$ & $86.5 \%$ & $74.7 \%$ & $94.6 \%$ \\
\hline Other/mixed & $12.5 \%$ & $13.8 \%$ & $23.6 \%$ & $5.3 \%$ & $11.9 \%$ & $13.5 \%$ & $25.3 \%$ & $5.4 \%$ \\
\hline $\mathrm{CPD}^{*}(\mathrm{SD})$ & $16.0(9.6)$ & $17.9(12.7)$ & $17.9(11.7)$ & $16.7(10.6)$ & $16.6(9.7)$ & $18.7(13.6)$ & $18.6(11.8)$ & $17.0(11.0)$ \\
\hline
\end{tabular}

Australia. Language was used as a proxy for Australian ethnicity ("English-speaking" = white, "non-English speaking" = non-white), as is consistent with the Australian census.

\section{Knowledge of health effects}

Respondents were asked to state whether they believed smoking causes heart disease, stroke, impotence, lung cancer in smokers, and lung cancer in non-smokers. Respondents were also asked to state whether they believed any of the following chemicals were included in cigarette smoke: cyanide, arsenic, and carbon monoxide. Response categories were "Yes", "No," or "Don't know."

Exposure to anti-smoking media and warning labels Exposure to anti-smoking media was measured by asking: "In the past 6 months, how often, if at all, have you noticed advertising or information that talks about the dangers of smoking, or encourages quitting?" Responses were given on a five-point Likert scale where $1=$ "Never" and $5=$ "Very often". Respondents were then asked whether they had noticed such information in each of nine specific locations ("Yes" or "No"). Exposure to warning labels was measured by asking: "In the last month, how often, if at all, have you noticed the warning labels on cigarette packages?" using the same five-point scale as for anti-smoking media.

\section{Analysis}

SPSS (version 12.0) was used for all statistical analyses. Logistic regression analyses were conducted to predict knowledge of health effects and intentions to quit. Knowledge of health effects were coded as 0 ("Not caused by smoking"//"Don't know") and I ("Caused by smoking"); intentions to quit were coded as 0 ("No plan to quit") and 1 ("Plans to quit sometime in the future"). Analyses were conducted on both weighted and unweighted data. There were no significant differences between analyses of weighted and unweighted data; unless otherwise noted, weighted results are presented below.

\section{RESULTS}

\section{Sample characteristics}

Table 1 presents the weighted and unweighted sample characteristics for each country.

\section{Knowledge of health effects and smoke constituents}

Table 2 presents smokers' knowledge of health effects by country. Most smokers reported that smoking causes lung cancer and heart disease, fewer believed that smoking causes stroke and lung cancer among non-smokers, whereas less than half agreed that smoking causes impotence. There was a significant difference between countries in the total number of diseases endorsed by respondents $(F[3,9024]=75.5$,

Table 2 Knowledge of health effects from smoking $(n=9058)$

\begin{tabular}{lllllll}
\hline \multirow{2}{*}{ Health effect } & \multicolumn{3}{l}{ Proportion who agree } & & & \\
\cline { 2 - 5 } & CAN & AUS & USA & UK & Overall & Odds of planning to quitt \\
(95\% CI)
\end{tabular}

*Significant differences between countries $(p<0.001)$.

†Odds of planning to quit smoking (0: No plan, 1: Plan) are adjusted for age, sex, income, ethnicity, and cigarettes smoked per day.

Bolded values indicate diseases that are listed in health warnings on packages in each country.

$\mathrm{Cl}$, confidence interval. 
Table 3 Knowledge of tobacco constituents $(n=9058)$

\begin{tabular}{|c|c|c|c|c|c|c|}
\hline \multirow[b]{2}{*}{ Smoke contains... } & \multicolumn{5}{|c|}{ Proportion who agree } & \multirow{2}{*}{$\begin{array}{l}\text { Odds of planning to quitt } \\
(95 \% \mathrm{CI})\end{array}$} \\
\hline & CAN & AUS & USA & UK & Overall & \\
\hline Carbon monoxide & $90.7 \%$ & $82.6 \%$ & $85.1 \%$ & $64.6 \%$ & $80.3 \% *$ & $1.72(1.51$ to 1.94$)$ \\
\hline Arsenic & $57.7 \%$ & $41.1 \%$ & $42.1 \%$ & $16.9 \%$ & $38.9 \% *$ & $1.59(1.41$ to 1.75$)$ \\
\hline Cyanide & $71.7 \%$ & $44.4 \%$ & $51.6 \%$ & $25.1 \%$ & $47.6 \% *$ & $1.66(1.49$ to 1.84$)$ \\
\hline \multicolumn{7}{|c|}{ Total constituents reported } \\
\hline 0 & $5.9 \%$ & $12.4 \%$ & $11.7 \%$ & $30.5 \%$ & $15.5 \% *$ & Reference \\
\hline 1 & $19.3 \%$ & $36.2 \%$ & $32.3 \%$ & $43.7 \%$ & $33.1 \% *$ & 1.44 (1.24 to 1.67$)$ \\
\hline 2 & $23.8 \%$ & $22.1 \%$ & $21.4 \%$ & $14.4 \%$ & $20.3 \% *$ & $1.90(1.60$ to 2.25$)$ \\
\hline 3 & $51.1 \%$ & $29.2 \%$ & $34.6 \%$ & $11.3 \%$ & $31.1 \% *$ & 2.41 (2.05 to 2.83$)$ \\
\hline
\end{tabular}

*Significant differences between countries $(p<0.001)$.

†Odds of planning to quit smoking $(0=$ No plan, $1=$ Plan $)$ are adjusted for age, sex, income, ethnicity, and cigarettes smoked per day.

Bolded values indicate constituents that are listed on packages in each country.

$\mathrm{Cl}$, confidence interval.

$\mathrm{p}<0.001)$. Canadian smokers endorsed a greater number of diseases than smokers from the other three countries $(\mathrm{p}<0.001)$, while Australian respondents were more likely to endorse diseases than US respondents $(p=0.005)$. Between-country differences were also observed for all individual diseases, with the exception of lung cancer among smokers. Most notably, almost twice as many Canadian respondents reported that smoking causes impotence relative to respondents from the USA, UK, and Australia. Table 2 also indicates the diseases that are included on health warnings within each country (see bolded values).

Table 2 also indicates that planning to quit smoking was positively associated with health knowledge. The odds of planning to quit were greater among smokers who endorsed each of the five diseases, and increased in a linear fashion with the total number of health effects reported. This pattern was observed within respondents of each country, as well as across countries, with no significant health effect by country interactions.

Table 3 provides smokers' knowledge of tobacco smoke constituents. Smokers were most likely to agree that tobacco smoke contains carbon monoxide and least likely to agree that arsenic is contained in tobacco smoke. Similar to the results for health knowledge, Canadian smokers were more likely to agree that tobacco smoke contains each of the three smoke constituents relative to US, UK, and Australian smokers. Note that the proportions in table 3 are in bold for countries in which the constituents were printed on cigarette packages at the time of the survey.

\section{Health knowledge and labelling policy}

A majority of respondents reported noticing information about the dangers of smoking "often" " or "very often" in the last six months: CAN 59.4\%, USA $60.4 \%$, UK 55.6\%, AUS $61.0 \%$. Table 4 indicates the sources of anti-smoking information for each country. "Cigarette packages" were a

Table 4 Sources of information on the dangers of smoking and anti-smoking media $(n=9058)$

\begin{tabular}{lrrrrl}
\hline Source & CAN & AUS & UK & USA & Overall \\
\hline TV & $88.2 \%$ & $90.4 \%$ & $83.9 \%$ & $86.2 \%$ & $87.7 \%$ \\
Cigarette packages & $84.3 \%$ & $69.3 \%$ & $56.1 \%$ & $46.7 \%$ & $64.6 \%$ \\
Magazine/newspaper & $66.1 \%$ & $34.4 \%$ & $62.6 \%$ & $62.8 \%$ & $64.1 \%$ \\
Poster & $57.4 \%$ & $43.2 \%$ & $51.3 \%$ & $58.6 \%$ & $56.2 \%$ \\
Radio & $40.7 \%$ & $42.7 \%$ & $26.1 \%$ & $45.2 \%$ & $38.9 \%$ \\
Leaflets & $35.3 \%$ & $32.6 \%$ & $37.7 \%$ & $24.6 \%$ & $33.2 \%$ \\
Shops/stores & $25.7 \%$ & $39.0 \%$ & $14.0 \%$ & $18.5 \%$ & $24.5 \%$ \\
Movie theatre & $8.5 \%$ & $12.7 \%$ & $11.1 \%$ & $10.1 \%$ & $11.1 \%$ \\
Internet & $10.4 \%$ & $6.4 \%$ & $4.1 \%$ & $12.4 \%$ & $8.4 \%$ \\
\hline
\end{tabular}

prominent source of health information in all four countries, particularly within Canada.

Smokers were also asked how often, if at all, they noticed cigarette warning labels in the last month. A logistic regression was conducted to examine the extent to which noticing cigarette warning labels was associated with health knowledge (table 5). The results indicate between-country differences in health knowledge: as with the bivariate analyses reported in table 2, Canadian respondents demonstrated an overall greater knowledge of the health effects of smoking. The findings also indicate that noticing the health warnings on cigarette packages was positively associated with health knowledge, after adjusting for noticing antismoking media in general. In other words, smokers who noticed the health warnings were more likely to agree that smoking causes each of the five diseases listed in table 5, adjusting for demographic variables and smoking behaviour.

Finally, analyses were conducted to compare health knowledge between smokers with and without health warnings on their cigarette packages. Countries were coded either as " 0 " (No health warning) or " 1 " (Health warning) for each disease and constituent listed in tables 2 and 3. Levels of health knowledge were then compared between respondents in countries with and without health warnings using logistic regression analysis. (Note that analyses were only run for diseases and constituents for which there were differences in labelling between the four countries). As fig 2 indicates, health knowledge was significantly greater among respondents in countries with health warnings, even after controlling for the number of other information sources cited by respondents. For example, smokers were 3.13 times more likely to say that tobacco smoke contains carbon monoxide when this information was printed on cigarette packages. ${ }^{*}$

\section{DISCUSSION}

It is commonly assumed and often argued by the tobacco industry that smokers are adequately informed about the health risks of smoking. ${ }^{18} 3435$ This study clearly demonstrates that this assumption is false. The findings indicate significant gaps in smokers' understanding of the risks of smoking: most, but not all, smokers reported that smoking causes heart disease and lung cancer in smokers-health consequences that have been established for over 25 years; more than a quarter of smokers did not believe that smoking caused stroke; and fewer than half of smokers believed that smoking causes impotence. Smokers' knowledge of toxic constituents in tobacco smoke was also unacceptably low.

"Note that carbon monoxide yields are listed on Canadian and Australian package, while one of the four US warning messages mentions carbon monoxide. 
Table 5 Predictors of health knowledge $(n=9058)$

\begin{tabular}{|c|c|c|c|c|c|}
\hline & \multicolumn{5}{|c|}{ Adjusted odds* $(95 \% \mathrm{Cl})$ of believing smoking causes.... } \\
\hline & Heart disease & Stroke & Impotence & $\begin{array}{l}\text { Lung cancer } \\
\text { (smokers) }\end{array}$ & $\begin{array}{l}\text { Lung cancer } \\
\text { (non-smokers) }\end{array}$ \\
\hline \multicolumn{6}{|l|}{ Country } \\
\hline CAN (reference) & 1.00 & 1.00 & 1.00 & 1.00 & 1.00 \\
\hline USA & $0.72(0.59$ to 0.89$)$ & $0.64(0.55$ to 0.75$)$ & $0.35(0.31$ to 0.40$)$ & $1.09(0.81$ to 1.48$)$ & 0.60 (0.52 to 0.70$)$ \\
\hline UK & $0.95(0.77$ to 1.18$)$ & $0.51(0.44$ to 0.59$)$ & $0.41(0.36$ to 0.47$)$ & $0.98(0.74$ to 1.31$)$ & $0.84(0.72$ to 0.98$)$ \\
\hline AUS & $0.82(0.66$ to 1.01$)$ & 0.90 (0.77 to 1.06$)$ & $0.37(0.33$ to 0.42$)$ & $0.90(0.68$ to 1.19$)$ & $0.55(0.47$ to 0.64$)$ \\
\hline \multicolumn{6}{|l|}{ Noticing anti-smoking } \\
\hline information & 1.20 (1.04 to 1.39$)$ & $1.16(1.04$ to 1.36$)$ & 1.05 (0.96 to 1.15$)$ & $1.10(0.90$ to 1.34$)$ & 1.11 (1.15 to 1.41$)$ \\
\hline Noticing warning labels & 1.20 (1.04 to 1.38$)$ & $1.23(1.11$ to 1.26$)$ & 1.14 (1.05 to 1.24$)$ & 1.31 (1.08 to 1.61$)$ & 1.27 (1.15 to 1.41$)$ \\
\hline
\end{tabular}

* Odds of believing smoking causes disease (0: No/Don't know, 1: Yes).

Odds ratios are adjusted for age, sex, income, ethnicity, and cigarettes smoked per day.

$\mathrm{Cl}$, confidence interval.

It is important to note that these results derive from smokers in among the most affluent, most highly educated countries in the world and in countries with among the most comprehensive tobacco control policies. We would expect health knowledge to be substantially lower among the majority of the world's smokers, particularly those living in lower and middle income countries where resources for tobacco control are non-existent or lower by orders of magnitude.

The findings also indicate that health warnings on cigarette packages are a prominent source of health information. Approximately two-thirds of smokers cited cigarette packages as a source of health information, with a significant association between the strength of package health warnings (as depicted in fig 1) and the likelihood of citing packages as a source of health information. In short, larger, more comprehensive warnings were more likely to be cited as a source of health information. For example, over $84 \%$ of smokers living in Canada-the country with the strongest health warnings-cited packages as a source of health information, compared with only $47 \%$ of those in the USA, the country with the weakest health warnings.
Not only were health warnings self-identified as an important source of health information about smoking, but also an effective means of communicating health information. The results provide evidence at both the individual and country-level that health warnings on cigarette packages are strongly associated with health knowledge. First, noticing labels was strongly associated with endorsing each of the five health effects, after controlling for smoking behaviour, demographic variables, and the frequency of noticing antimedia in general. Smokers who reported noticing warnings were between 1.5-3.0 times more likely to believe in each health effect. Second, in all five cases where labelling policies differed between countries, smokers living in countries with government mandated warnings reported greater health knowledge. This pattern is best illustrated in the case of smokers' knowledge of impotence. Canada was the only country where packages carry warnings about impotence, and accordingly, Canadian smokers were almost three times more likely than smokers from the other three countries to believe that smoking causes impotence. This finding provides a measure of specificity for the effect of warning labels; we are unaware of any media source or educational initiative in

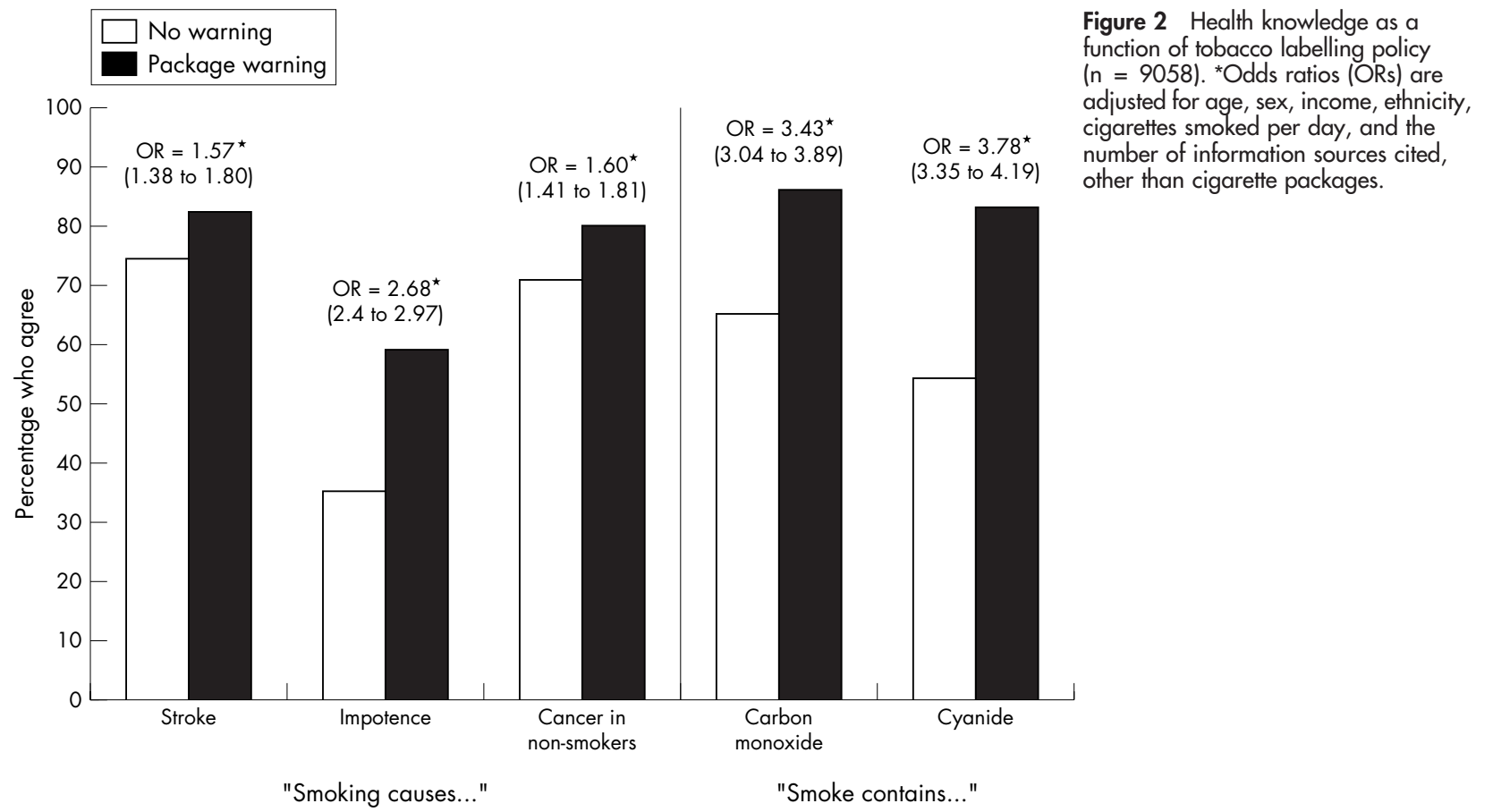


Canada, other than the package warnings, to have highlighted the risks of impotence. Clearly, smokers in the other four countries may have been exposed to information on impotence and other health risks not listed on the pack; however, this only strengthens the findings on the effectiveness of the warnings. For example, in 1998 and 1999, the state of California conducted a \$22 million mass media campaign that included messages linking smoking and impotence. $^{36}$ As might be expected, California smokers in the current study were more likely to endorse impotence as a cause of smoking than other US respondents, yet they were no more likely to endorse impotence than Canadian respondents. This example underscores the cost-effectiveness of package warnings: California spent several millions of dollars to attain levels of awareness that were achieved in Canada via warning labels that were introduced at little or no cost to the government.

Finally, health knowledge was strongly associated with intentions to quit among smokers in all four countries. This finding supports previous evidence that, although awareness and acceptance of the health risks of smoking may not be a sufficient condition for quitting, it is likely a necessary one for most smokers and serves an important source of motivation.

\section{Limitations}

Health knowledge can be assessed several ways. The measures used in the current study constitute a relatively low threshold for knowledge or risk perception. Indeed, respondents were not asked to recall smoking-related diseases unprompted, nor were they asked to estimate the likelihood or severity of smoking-related disease. Had these measures been used, the findings would inevitably have yielded relatively lower levels of "health knowledge" than those reported here. In addition, the cross-sectional nature of these data cannot address the directionality of the associations between health knowledge, warnings, and other variables. For example, it may be that smokers with greater health knowledge were more likely to attend to health warnings. Finally, the between-country differences in health knowledge may partly reflect concomitant efforts to inform the public of the health risks of smoking through other channels, such as mass media campaigns. However, this limitation is tempered by the fact that noticing the labels predicted health knowledge even after controlling for other sources of information, as well as by the specificity provided by the Canadian warnings in the case of impotence. Nonetheless, longitudinal data would help to clarify the causal nature of these associations.

\section{Implications}

Tobacco products remain the most lethal consumer product in every country in which they are sold. The US Surgeon

\section{What this paper adds}

Health warnings on tobacco products are a primary means of communicating with smokers; however, few studies have evaluated the impact of health warnings on consumer knowledge about tobacco risks. The current findings from adult smokers in four countries demonstrate that health warnings on cigarette packages are a prominent source of health information and an effective means of communicating specific disease risks. The findings also indicate that more comprehensive warnings - such as the graphic warnings on Canadian packages-are associated with greater health knowledge.
General recently reported a causal link between smoking and 28 individual diseases, including the leading causes of death in the western world. ${ }^{2}$ Remarkably, the list of known health risks continues to grow, with cancers of the stomach and acute myeloid leukemia among those most recently identified. Given this list, it would be folly to assume that smokers are currently, or likely ever will be, fully informed of the risks of smoking. Nevertheless, tobacco companies and governments are responsible for making every effort to ensure the highest levels of health knowledge possible. At present, however, tobacco consumers receive little information regarding the ingredients, additives, and chemical composition of their products. In countries such as the USA, chocolate bars carry more information about ingredients than cigarette packages.

The current findings indicate that large, graphic warnings on cigarette packages are an effective means of increasing health knowledge among smokers. Previous research also suggests that Canadian-style warnings provide substantial cessation benefits and enjoy widespread support among smokers. ${ }^{9526}$ The effectiveness of warning labels in communicating health effects suggests that warnings could also be used to address knowledge deficits in other areas, such as filter ventilation, the risks of "light" or "low-tar" cigarettes, and the effects of behavioural compensation. ${ }^{37-40}$ Given their universal reach, health warnings may also help to reduce the disparities in health knowledge by providing low-income smokers with regular access to health information. ${ }^{41}{ }^{42}$ Yet, despite growing evidence of their effectiveness, most governments remain reluctant to mandate comprehensive health warnings, while the tobacco industry continues to fight their introduction. ${ }^{43}$ The industry's opposition is understandable: they fear that strong warning labels will shrink their market and erode profits; the reluctance among governments and regulators is more puzzling.

\section{ACKNOWLEDGEMENTS}

The research was funded by grants from the R01 CA 100362 and P50 CAl11236 (Roswell Park Transdisciplinary Tobacco Use Research Center) from the National Cancer Institute of the United States, Robert Wood Johnson Foundation (045734), Canadian Institutes of Health Research (57897), National Health and Medical Research Council of Australia (265903), Cancer Research UK (C312/A3726), Canadian Tobacco Control Research Initiative (014578); Centre for Behavioural Research and Program Evaluation, National Cancer Institute of Canada/Canadian Cancer Society; and the CIHR Strategic Training Program in Tobacco Research. Role of the funding sources: The funding sources had no role in the study design, in the collection, analysis, and interpretation of data, in the writing of the report, and in the decision to submit the paper for publication.

\section{Authors' affiliations}

D Hammond, Department of Health Studies and Gerontology, University of Waterloo, Waterloo, Ontario, Canada

G T Fong, Department of Psychology, University of Waterloo

A McNeill, Division of Public Health \& Epidemiology, University College London, London, UK

R Borland, The Cancer Council, Victoria, Melbourne, Australia K M Cummings, Department of Health Behavior Roswell Park Cancer Institute, Buffalo, New York, USA

Competing interests: none declared

Contributions of authors: David Hammond conducted the analyses and was the principal author of the manuscript. Geoffrey T Fong, K Michael Cummings, and Ron Borland conceived of the study and each contributed to the writing of the manuscript, along with Ann McNeill.

Ethics approval: The study protocol was cleared for ethics by the Institutional Review Boards or Research Ethics Boards in each of the countries: the University of Waterloo (Canada), Roswell Park Cancer Institute (USA), the University of Illinois-Chicago (USA), the University of Strathclyde (UK), and The Cancer Council Victoria (Australia). 


\section{REFERENCES}

1 Murray CJ, Lopez AD. Alternative projections of mortality and disability by cause 1990-2020: Global Burden of Disease Study. Lancet 1997;349:1498-504.

2 US Department of Health and Human Services. The health consequences of smoking: a report of the Surgeon General. Atlanta, Georgia: Dept of Health and Human Services, Centers for Disease Control and Prevention, National Center for Chronic Disease Prevention and Health Promotion, Office on Smoking and Health; Washington, DC, 2004.

3 Janz N, Becker MH. The health belief model: a decade later. Health Educ $Q$ 1984;11:1-47.

4 Bandura A. Self-efficacy: toward a unifying theory of behavioral change. Psychol Rev 1977;84:191-215.

5 Ajzen I. The theory of planned behavior. Organ Behav Hum Decis Process 1991;50:179-211.

6 Nourjah P, Wagener DK, Eberhardt M, et al. Knowledge of risk factors and risk behaviours related to coronary heart disease among blue and white collar males. J Public Health Policy 1994; 15:443-59.

7 Romer D, Jamieson P. The role of perceived risk in starting and stopping smoking. In: Slovic, ed. Smoking: risk, perception, and policy. Thousand Oaks California: Sage, $2001 ; 65-80$.

8 Curry SJ, Grothaus L, McBride C. Reasons for quitting: intrinsic and extrinsic motivation for smoking cessation in a population-based sample of smokers. Addict Behav 1997;22:727-39.

9 Hammond D, McDonald PW, Fong GT, et al. The impact of cigarette warning labels and smoke-free bylaws on smoking cessation: evidence from former smokers. Can J Public Health 2004;95:201-4.

10 Hyland A, Li Q, Baver JE, et al. Predictors of cessation in a cohort of current and former smokers followed over 13 years. Nicotine Tob Res 2004;6(suppl 3):S363-69.

11 Health Canada. Baseline surveys: the health effects of tobacco and health warning messages on cigarette packages. Prepared by Environics Research Group, 2001.

12 Strecher VJ, Kreuter MW, Kobrin SC. Do cigarette smokers have unrealistic perceptions of their heart, cancer, and stroke risks? J Behav Med 1995; 16:153-68.

13 Lee C. Perceptions of immunity to disease in adult smokers. J Behav Med 1989;12:267-77.

14 McCoy SB, Gibbons FX, Reis TJ, et al. Perceptions of smoking risk as a function of smoking status. J Behav Med 1992;15:469-88.

15 Health Canada. Testing new health warning messages for cigarette packages: a summary of three phases of focus group research. Prepared by Environics Research Group, 2000.

16 Environics Research Group. Assessment of perceived health risks due to smoking. Prepared for Health Canada, 1999

17 Ayanian JZ, Cleary PD. Perceived risks of heart disease and cancer among cigarette smokers. JAMA 1999;281:1019-21.

18 Cummings KM, Hyland A, Giovino GA, et al. Are smokers adequately informed about the health risks of smoking and medicinal nicotine? Nicotine Tob Res 2004;6(suppl 3):S333-40.

19 Weinstein ND, Slovic P, Gibson G, et al. Public understanding of the illnesses caused by cigarette smoking. Nicotine Tob Res 2004;6:349-55.

20 Schoenbaum M. Do smokers understand the mortality effects of smoking? Evidence from the health and retirement survey. Am J Public Health 1997:87:755-9.

21 Weinstein ND. Accuracy of smokers' risk perceptions. Ann Behav Med 1998;20:135-40.
22 Frank E, Denniston M, Pederson L. Declines in smokers understanding of tobacco hazards between 1986 and 1998: a report from North Georgia. South Med J 2002;95:675-80

23 Stockwell TR, Rutley R, Clark K. Pesticides and other chemicals in cigarette tobacco. Med J Aust 1992; 157:68.

24 Centers for Disease Control and Prevention. Best practices for comprehensive tobacco control programs-August 1999. Atlanta, Georgia: US Department of Health and Human Services, Centers for Disease Control and Prevention, National Center for Chronic Disease Prevention and Health Promotion, Office on Smoking and Health, August, 1999.

25 Hammond D, Fong GT, McDonald PW, et al. The impact of the graphic Canadian warning labels on adult smoking. Tob Control 2003;12:391-5.

26 Hammond D, Fong GT, McDonald PW, et al. Graphic cigarette package warning labels do not lead to adverse outcomes: evidence from Canadian smokers. Am J Public Health 2004;94:1442-5.

27 Borland R. Tobacco health warnings and smoking-related cognitions and behaviours. Addiction 1997;92:1427-35.

28 Imperial Tobacco Ltd. The Canadian tobacco market at a glance. RJRMacdonald v. Attorney General of Canada, Exhibit AG-31, 1989.

29 Tandemar Research, P. f. H. C. Cigarette packaging study: The evaluation of new health warning messages (Rep. No. TR\#663022), 1996.

30 Borland R, Hill D. Initial impact of the new Australian tobacco health warnings on knowledge and beliefs. Tob Control 1997:6:317-25.

31 Aftab M, Kolben D, Lurie P. International cigarette labelling practices. Tob Control 1998;8:368-72.

32 Binson D, Canchola JA, Catania JA. Random selection in a national telephone survey: a comparison of the Kish, next-birthday, and last-birthday methods. J Off Stat 2000;16:53-60.

33 Singer E, van Hoewyk J, Maher MP. Experiments with incentives in telephone surveys. Public Opin Q 2000;64:171-88

34 Wilkenfeld J, Henningfield J, Slade J. Its time for a change: cigarette smokers deserve meaningful information about their cigarettes. J Natl Cancer Inst 2000;92:90-2

35 Cummings KM, Morley, Hyland A. Failed promises of the cigarette industry and its effect on consumer misperceptions about the health risks of smoking. Tob Control 2002;11(suppl I):i1 10-16.

36 Davis RM. The Marlboro Man needs Viagra (News Analysis). Tob Control 1998;7:227.

37 Shiffman S, Pillitteri JL, Burton SL, et al. Smokers' beliefs about "Light" and "Ultra Light" cigarettes. Tob Control 2001;10(suppl I):i17-23.

38 Borland R, Yong HH, King B, et al. Use of and beliefs about 'light' cigarettes in four countries: findings from the International Tobacco Control Policy Evaluation Survey. Nicotine Tob Res 2004;6(suppl 3):S31 1-21.

39 Kozlowski LT, White EL, Sweeney CT, et al. Few smokers know their cigarettes have filter vents. Am J Public Health 1998;88:681-2

40 Cummings KM, Hyland A, Bansal MA, et al. What do Marlboro Lights smokers know about low-tar cigarettes? Nicotine Tob Res 2004;6(suppl):S323-32.

41 Andersson P, Leppert J. Men of low socio-economic and educational level possess pronounced deficient knowledge about the risks factors related to coronary heart disease. J Cardiovasc Risk $2001 ; 8: 371-7$.

42 Price JH, Everett SA. Perceptions of lung cancer and smoking in an economically disadvantaged population. J Community Health 1994; 19:361-75.

43 Chapman S, Carter SM. "Avoid health warnings on all tobacco products for just as long as we can": a history of Australian tobacco industry efforts to avoid, delay and dilute health warnings on cigarettes. Tob Control 2003; 12(suppl III):iii13-22. 